\title{
Cooperation Pattern Analysis of Seasonal Inventory Impawn Financing Cheng Fan ${ }^{1, a, *}$

\author{
${ }^{1}$ School of Economics and Management, Nanjing Uninversity of Science and Technology, \\ Nanjing,China
} \\ a nlgchf@163.com
}

\begin{abstract}
Key words: Inventory impawn financing, Loan-to-value ratio, Shapley value.
\end{abstract}
\begin{abstract}
The massively increasing of micro, small and medium enterprises (SMEs) is prompting changes in the competition of enterprises and supply chains, which put forward higher requirements to risk controlling level of supply chain financing. The development and innovation of logistics financing provides an effective way to control risks to banks and other financial institutions. This paper researches on the decision-making behavior of the supply chain members composed of a supplier, a distributor and a logistics enterprise under the unified credit granting mode and the case of seasonal inventory impawn. The distributor's reorder and the loan-to-value ratio's decision in different cooperative models are considered as dependent variables. Then, based on Shapley-value theory, the possibility of the existence of alliance cooperation and the appropriate proportion of alliance earnings distributed by the members are validated. A numerical experiment is carried out to verify the conclusion. The result shows that in certain cases when the status of the supplier( as the core enterprise) below the logistics enterprise, cooperating can reduce the request of distributor's size and improve the union gains.
\end{abstract}

\section{Introduction}

There often occurs cash constraint in a supply chain when upstream and downstream enterprises do business of purchase and sales. Facing these questions, traditionally, cash-constrained enterprises may be borrowing from the bank, or get a loan from the core enterprise of supply chain. In practice, cash-constrained enterprises are usually small and medium-sized enterprises (SMEs). On the one hand, information asymmetry makes the bank unable to measure the risk accurately, on the other hand, the core enterprise is not usually expertise in financing, that may result in high risk, not reasonable profit, not abundant cash demand and so forth other problems. An effective way to control the risk is the SMEs transfer part of the ownership of their inventories as a pledge so that once the SMEs default, the core enterprise can take back the inventories to compensate for the losses. Moreover, the cooperation of banks and 3PLs can combine logistics, information flow and cash flow effectively, thus meet the demand of large amounts of money and realize the risk control at the mean time. By unified credit granting, the bank can entrust the loan business to SMEs in supply chain to a logistics enterprise familiar with the information of the supply chain members' logistics management, so as to realize the accurate control of the risks.

Early studies of enterprise operational management assume that decision-making of funds and logistics operation is separately. However, actual operational of the enterprise decision-making is usually restricted by funding constraints. Rosenblatt (1981) ${ }^{1}$ firstly introduced funding constraints into inventory decisions. Then Li, Shubik and Sobel $(2005)^{2}$ derived a dynamic model of making inventory and cash flow decisions at the mean time under the uncertain market demand to maximize expected return. Protopappa-Sieke and Seifert $(2010)^{3}$ researched the impact of payment delay under funds constraints to business. Considering the bank loan, Buzacott and Zhang (2004) $)^{4}$ built a Stackelberg game model, discussed the order decision of a retailer who sales seasonal goods under uncertain demand and given interest rate. Dada and $\mathrm{Hu}(2008)^{5}$ gave an approximate study based on newsvendor model. These studies above assumed that enterprises loan from banks directly, which ignored the role of commercial credit and mortgage guarantee in the supply chain. Gupta and 
Wang (2009) ${ }^{6}$ studied the coordination of the supply chain under funds constraints, thinking that commercial credit is now the most common methods that suppliers subsidies retailers holding costs. Thangam and Uthaykumar (2009) ${ }^{7}$ set the demand the function of sales price and the trade credit period, built an economic production quantity model of perishable goods under two levels of trade credit financing. Caldentey and Haugh $(2009)^{8}$ studied the decision of funds-constrained retailer and suppliers in a Stackelberg game, analyzed the supply chain contract design when the retailer can conduct financial hedging. Lai (2009) ${ }^{9}$ compared the efficiency of supply chain under different model of commercial credit.

As a new pattern in the secured loan, inventory impawn financing business is complex and developing rapidly, so determines some important risk control indicators such as loan-to-value ratios and interest ratios. Besanko and Thakor $(1987)^{10}$ and Chan and Thakor (1987) ${ }^{11}$ studied the interest rate index of secured loan from the perspective of information economics, the conclusion were that the bank can distinguish the various risks of borrowing enterprises by designing the assembly of collateral and interest rate. Rajan and Winton (1995) ${ }^{12}$ believed that the number of collateral has an positive correlation with the risk. Omiccioli (2005) ${ }^{13}$ provided a model related accounts receivable financing studied factors affecting the number of accounts receivable guarantee.The study of Buzacott and Zhang (2004) come to a conclusion that enterprises with different amount of inventories will make reorder decisions according to the interest rate and the loan-to-value ratio, and banks can also make credit rationing through limiting the lending quotas of credit contracts.

On the basis of predecessors' research, the author will continue to explore the decision-makings of the supply chain members in inventory impawn financing under conditions of uncertain demand, seasonal goods and unified credit granting model. Differs to predecessors', different patterns of cooperate models are built. The possibility of the existence of alliance cooperation and the appropriate proportion of alliance earnings distributed by the members base on the Shapley method are studied. This paper is organized as follows: After the built and the description of the model in section 2, the decision-making of the supply chain members are studied in the angle of the game in section 3. Section 4 discusses the possibility of alliance cooperation and the way to realize it. Then comes the numerical experiment in section 5. The conclusion is draw in section 6 .

\section{Model}

\subsection{Model description}

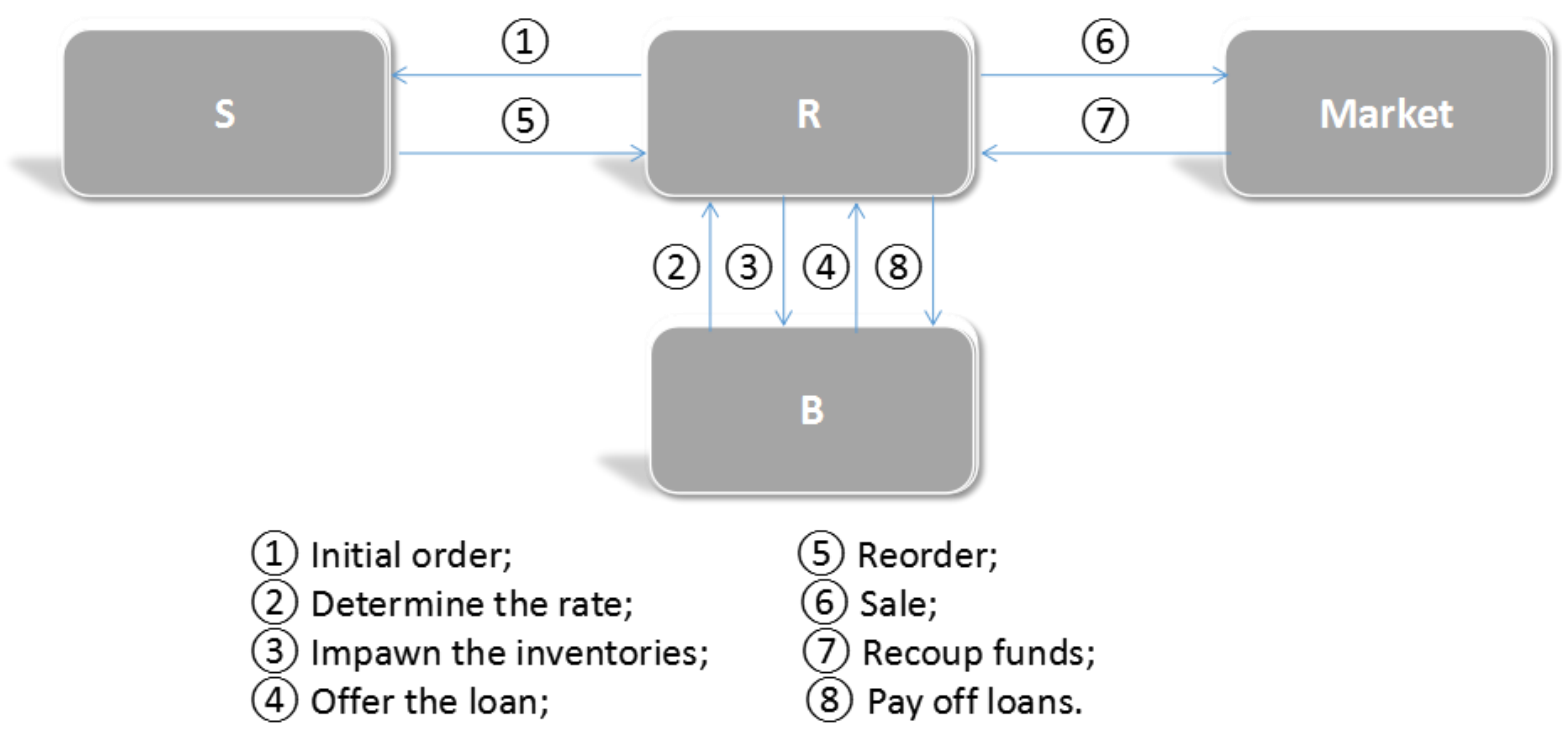

Figure 1operation procedure 
The forecast of the market demand is the key factor for supply chain members to participate in the competition and cooperation. This paper assumes that the supply chain are composed with a supplier (S), a retailer (R) and a logistics enterprise (B) as the partner of a bank under the unified credit granting model. As the core enterprise of the supply chain, $\mathrm{S}$ can get the history of the sales data by market feedback and obtain the market demand of general distribution curve through experts' predict. S would fully share the information with R (under funds constraint) and B. Assume $\mathrm{B}$ is underside risk averted, the goods is seasonal (bargain price below warehousing costs), the operation procedure is explained in the figure below:

$\mathrm{R}$ use its own funds for the initial order, and apply for the loan to B in the way of inventory impawn financing. $\mathrm{B}$ will determine the loan-to-value ratio on the target of controlling risks and maximizing interests after received the apply. $\mathrm{R}$ will reorder from $\mathrm{S}$ once received the loan from $\mathrm{B}$, then sale the inventories and recoup funds. Under the unified credit granting model, the logistics enterprise can make sure that the inventories impawned sales first, and once the income of impawned inventories can not repay the loan, the logistics enterprise can control the inventories reordered. The income will be saved into the closed account until it pays off the loan.

In order to analyze the role of supply chain cooperation, this paper puts forward three models of cooperating.

Model 1: S and R. S will buy back part of the unsold goods to promote sales.

Model 2: $\mathrm{R}$ and $\mathrm{B}$. $\mathrm{R}$ will pay off the loan in a certain probability from other way when default happens.

Model 3: S and B. S will bear part of the loss of B when fault happens.

\subsection{Symbols definition}

$p$ : sales price; $c_{1}$ : purchase price; $c_{2}$ : the cost of $\mathrm{S} ; c^{\prime}$ : bargain price;

$s$ : warehouse charges; $s^{\prime}$ : warehouse charges of $\mathrm{B} ; a$ : interest rate;

$a^{\prime}$ : the interest cost of $\mathrm{B} ; \quad Q_{1}$ :repurchase proportion;

$Q_{2}$ :probability of repayment when fault happens; $Q_{3}$ : loss proportion bear by $\mathrm{S}$.

Assume the market demand $\xi$ follows the distribution function of $F(x)=P(\xi<x)$, and the destiny function is $f(x)=F^{\prime}(x)$, which meets increasing failure rate, that is, when $a>b$, $\frac{f(a)}{F(a)}<\frac{f(b)}{F(b)}$. According to the market rule, there is $p>c_{1}>c_{2}>s>c^{\prime}$; the premise of applying for loan for $\mathrm{R}$ is that $p>(1+a) c_{1}+s$. Thus the interest rate should meet the condition $a<\frac{p-s-c_{1}}{c_{1}}$.

Assume the loan-to-value ratio is $\omega$, the initial inventory of $\mathrm{R}$ is $q_{0}$, the reorder amount is $q$. When the initial inventories are all impawned, $\omega=q / q_{0}$. Since B is underside risk averted, assume $L$ is the maximum loss B can bear and $L$ is the function of the loan and the warehouse charges, there is $L=l v_{0}=l\left(c_{1} q+s^{\prime} q_{0}\right) . l(0<l<1)$ is the loss degree. Considering the condition of underside risk aversion, $P($ loss $>l c q) \leq \beta$.

\section{Different decision-makings in different game patterns}

3.1 R's earnings and the decision of reorder. In different game patterns, $R$ 's earnings is related to the loan-to-value ratio, the interest rate and the decision of $\mathrm{B}$ and $\mathrm{S}$. R's objective is to maximize his own profit, the author use $E R(0,0,0), E R(1,1,0), E R(1,0,1), E R(0,1,1), E R(1,1,1)$ as the expected earnings of noncooperation, model 1 , model 2 , model 3 , and cooperation respectively.

When there is no cooperation, according to the conditions, if not default, $\mathrm{R}$ 's earnings is:

$R(\xi)=p \min \left\{\xi, q+q_{0}\right\}+c^{\prime} \max \left\{0, q+q_{0}-\xi\right\}-(1+a) c_{1} q-c_{1} q_{0}-s q_{0}$ 
When $\xi \geq \xi_{x}=\frac{(1+a) c_{1} q+s q_{0}-c^{\prime} q_{0}}{p-c^{\prime}}$, R will not fault, so R's expected earnings is:

$$
\begin{aligned}
& E R(0,0,0)=\left[1-F\left(q+q_{0}\right)\right]\left[p\left(q+q_{0}\right)-(1+a) c_{1} q-s q_{0}-c_{1} q_{0}\right]+\int_{0}^{\xi_{x}}\left(c^{\prime} q-c_{1} q_{0}\right) f(x) d x \\
& \quad+\int_{\xi_{x}}^{q+q_{0}}\left[p x+c^{\prime}\left(q+q_{0}-x\right)-(1+a) c_{1} q-s q_{0}-c_{1} q_{0}\right] f(x) d x \\
& =p\left(q+q_{0}\right)-(1+a) c_{1} q-s q_{0}-c_{1} q_{0}-\left(p-c^{\prime}\right)\left(q+q_{0}\right) F\left(q+q_{0}\right)+\left[(1+a) c_{1} q\right. \\
& \left.\quad+s q_{0}-c^{\prime} q_{0}\right] F\left(\xi_{x}\right)+\left(p-c^{\prime}\right) \int_{\xi_{x}}^{q+q_{0}} x f(x) d x
\end{aligned}
$$

When the loan-to-value ratio and interest rate is given, if $\mathrm{R}$ impawn all the inventories,

$$
F\left(q+q_{0}\right)=\frac{n}{g}+\frac{h}{g} F\left(\xi_{x}\right)
$$

And

$$
n=p(1+\omega)-(1+a) c_{1} \omega-s-c_{1}, g=\left(p-c^{\prime}\right)(1+\omega), h=(1+a) c_{1} \omega+s-c^{\prime}
$$

The value of $F\left(q+q_{0}\right)$ should be in $(0,1)$. Apparently, $\frac{n}{g}<F\left(q+q_{0}\right)<\frac{n+h}{g}$, there is $\frac{n}{g}=\frac{p-s-c_{1}+\left[p-(1+a) c_{1}\right] \omega}{\left(p-c^{\prime}\right)(1+\omega)}>0$ and $\frac{n+h}{g}=\frac{p(1+\omega)-c_{1}-c^{\prime}}{p(1+\omega)-c^{\prime}-\omega c^{\prime}}<1$, so the solution exists.

$$
\frac{\partial^{2} E R(0,0,0)}{\partial q_{0}{ }^{2}}=-\left(p-c^{\prime}\right)(1+\omega)^{2} F\left(q+q_{0}\right) \frac{f\left(q+q_{0}\right)}{F\left(q+q_{0}\right)}+\frac{\left[(1+a) c_{1} \omega+s-c^{\prime}\right]^{2}}{p-c^{\prime}} F\left(\xi_{x}\right) \frac{f\left(\xi_{x}\right)}{F\left(\xi_{x}\right)}<0
$$

$F(x)$ is a monotone increasing function, there must be a only solution $q_{0}$ that make the earnings obtain maximum value, the ${ }^{q_{0}^{*}}$ meet the condition $F\left(q+q_{0}\right)=\frac{n}{g}+\frac{h}{g} F\left(\xi_{x}\right)$, the optimal amount of reorder is ${ }^{2} q_{0}^{*}$. While the amount of initial greater than ${ }^{*}$, R will not impawn all the inventories, the amount of reorder would be the function of . Assume $q=q_{v}\left(q_{0}\right)$, let $\frac{\partial E R(0,0,0)}{\partial q}=0$,we have

$$
F\left(q+q_{0}\right)=\frac{p-(1+a) c_{1}\left[1-F\left(\xi_{x}\right)\right]}{p-c^{\prime}}
$$

There is a $q$ meet the condition above, assume it is $\bar{q}$. Then

$$
\begin{aligned}
& \frac{\partial^{2} E R(0,0,0)}{\partial q^{2}}=-\left(p-c^{\prime}\right) f\left(q+q_{0}\right)+f\left(\xi_{x}\right) \frac{\left[(1+a) c_{1}\right]^{2}}{p-c^{\prime}}=\left[\frac{(1+a) c_{1}}{p-c^{\prime}}\right]^{2} f\left(\xi_{x}\right)-f\left(q+q_{0}\right)<0 \\
& \text { If } \bar{q}=0 \\
& p-(1+a) c_{1}\left[1-F\left(\frac{s-c^{\prime}}{p-c^{\prime}}\right)\right]=\left(p-c^{\prime}\right) F\left(q_{0}\right)
\end{aligned}
$$

Let $q_{0}^{* *}$ meet the condition above, the reorder is zero. Above all, $\mathrm{R}$ 's reorder is

$$
q(\mathrm{O}, \mathrm{O}, \mathrm{O})= \begin{cases}\omega q_{\mathrm{o}}, & q_{\mathrm{o}} \leq q_{\mathrm{O}}^{*} \\ \bar{q}, & q_{\mathrm{O}}^{*}<q_{\mathrm{o}} \leq q_{\mathrm{O}}^{* * *} \\ \mathrm{O}, & q_{\mathrm{o}}>q_{\mathrm{O}}^{* * *}\end{cases}
$$

In other game patterns, the expected earnings and reorder decision will be affected by the 
Proportion $Q_{1}, Q_{2}$.

\subsection{B's earnings and the decision of reorder}

If there is no cooperation, when $\xi \leq \xi_{x}$, R will default, the loss of $\mathrm{B}$ is $\operatorname{loss}(\xi)=c_{1} q(1+a)+s q_{0}-p \xi-c^{\prime}\left(q_{0}-\xi\right)$

According to the condition of underside risk aversion,

$$
P\left\{(1+a) c_{1} q+\left(s-c^{\prime}\right) q_{0}-\left(p-c^{\prime}\right) \xi>l c_{1} q\right\}=F\left[\frac{(1+a-l) c_{1} q+\left(s-c^{\prime}\right) q_{0}}{p-c^{\prime}}\right] \leq \beta
$$

When $0<q_{0} \leq q_{0}^{*}, q=\omega q_{0}$, so that

$$
\omega \leq \omega_{0}^{*}=\frac{\left(p-c^{\prime}\right) F^{-1}(\beta)-\left(s-c^{\prime}\right) q_{0}}{(1+a-l) c_{1} q_{0}}
$$

When, the loan-to-value ratio will change with the amount of R's initial inventories, there is no underside risk. $\mathrm{B}$ will determine the loan-to-value ratio according to the reorder decision of $\mathrm{R}$. When $0<q_{0} \leq q_{0}^{*}$, take B's expected earnings with respect to loan-to-value ratio,let $\frac{\partial E B(0,0,0)}{\partial \omega}=0$

$$
\omega_{0}=\frac{\left(p-c^{\prime}\right) F^{-1}\left(\frac{a-a^{\prime}}{1+a}\right)-s q_{0}+c^{\prime} q_{0}}{(1+a) c_{1} q_{0}}
$$

When $q_{0}^{*}<q_{0} \leq q_{0}^{* *}, q=\bar{q}=q_{v}\left(q_{0}\right)$, let, the solution is the same with the solution above, considering the safety of the funds, we can make the ratio of expected amount of reordered goods and the amount of initial inventories as the loan-to-value ratio. The solution of loan-to-value ratio is the smaller one. When $q_{0}>q_{0}^{* *}$, the amount of reorder is zero, so the loan-to-value ratio is zero. The decision of loan-to-value ratio is

$$
\omega(0,0,0)= \begin{cases}\min \left(\omega_{0}^{*}, \omega_{0}\right), & 0<q_{0} \leq q_{0}^{*} \\ \min \left(\frac{\bar{q}}{q_{0}}, \omega_{0}\right), & q_{0}^{*}<q_{0} \leq q_{0}^{* *} \\ 0, & q_{0}>q_{0}^{* *}\end{cases}
$$

We can get the solutions in other game patterns similarly.

\subsection{S's earnings and the decision of reorder}

In the pattern of noncooperation, S's earnings is related with R's reorder amount, is

$$
E S(0,0,0)=\left(c_{1}-c_{2}\right)\left(q+q_{0}\right)
$$

In other patterns, the solution are

$$
\begin{aligned}
& E S(1,1,0)=\left(c_{1}-c_{2}\right)\left(q+q_{0}\right)-c_{1} Q_{1}\left(q+q_{0}\right) F\left(q+q_{0}\right)+c_{1} Q_{1} q F\left(\xi_{y}\right)+c_{1} Q_{1} \int_{\xi_{y}}^{q+q_{0}} x f(x) d x \\
& \begin{aligned}
E S(0,1,1)= & \left(c_{1}-c_{2}\right)\left(q+q_{0}\right)-F\left(\xi_{x}\right)\left[\left(c_{1}-c_{2}\right)\left(q+q_{0}\right)+Q_{3}(1+a) c_{1} q+Q_{3} s q_{0}-Q_{3} c^{\prime} q_{0}\right] \\
& \quad-Q_{3} \int_{0}^{\xi_{x}} x f(x) d x
\end{aligned} \\
& \begin{aligned}
& E S(1,1,1)=\left(c_{1}-c_{2}\right)\left(q+q_{0}\right)-c_{1} Q_{1}\left(q+q_{0}\right) F\left(q+q_{0}\right)+c_{1} Q_{1} q F\left(\xi_{y}\right)+c_{1} Q_{1} \int_{\xi_{y}}^{q+q_{0}} x f(x) d x \\
& \quad-Q_{3} \int_{0}^{\xi_{y}} x f(x) d x-F\left(\xi_{y}\right)\left\{\left(c_{1}-c_{2}\right)\left(q+q_{0}\right)+Q_{3}\left[(1+a) c_{1} q+s q_{0}-c^{\prime \prime} q_{0}\right]\right\}
\end{aligned}
\end{aligned}
$$




\section{Cooperative game}

Cooperation game theory studies how alliance members distribute the earnings by cooperating. There are two basic conditions that the cooperation alliance exist:

(1) To the alliance, the earnings overall is greater than the sum of its business separately for each member of the income;

(2) In the interior of the alliance, the earnings distributed to each member is much than the income separately.

Shapley come up with the concept of Shapley value to solve the n-people bargaining game, it gave a good method to the distributed proportion of the earnings. The starting point of Shapley value method is based on the margin contribution of each member to the alliance to guarantee the fairness of distribution. Shapley-value method can do better in reflecting the parries contribution to the alliance, so it's more reasonable.

In this paper, when the alliance earnings is greater than the sum of the income separately, the members will adopt the alliance, otherwise, the alliance will not exist. The proportion will be determined by the contribution to the alliance.

Table 1cooperative pattern and the earning

\begin{tabular}{|l|l|l|}
\hline number & Cooperative pattern & earnings \\
\hline 1 & $\{\mathrm{R}\}$ & $b_{1}$ \\
\hline 2 & $\{\mathrm{~S}\}$ & $b_{2}$ \\
\hline 3 & $\{\mathrm{~B}\}$ & $b_{3}$ \\
\hline 4 & $\{\mathrm{R}, \mathrm{S}\}$ & $b_{1,2}$ \\
\hline 5 & $\{\mathrm{R}, \mathrm{B}\}$ & $b_{1,3}$ \\
\hline 6 & $\{\mathrm{~S}, \mathrm{~B}\}$ & $b_{2,3}$ \\
\hline 7 & $\{\mathrm{R}, \mathrm{S}, \mathrm{B}\}$ & $b_{1,2,3}$ \\
\hline
\end{tabular}

According to the Shapley-value method, the subset contained $R$ is $\{R\},\{R, S\},\{R, B\},\{R, S$, $\mathrm{B}$,$\} . Make R, S, B the code 1, 2, 3. The solution of R's earnings is in the table below.$

Table 2R's distributed earnings

\begin{tabular}{|l|l|l|l|l|}
\hline $\mathrm{S}$ & $\{1\}$ & $\{1,2\}$ & $\{1,3\}$ & $\{1,2,3\}$ \\
\hline $\mathrm{v}(\mathrm{S})$ & $b_{1}$ & $b_{1,2}$ & $b_{1,3}$ & $b_{1,2,3}$ \\
\hline $\mathrm{v}(\mathrm{S}-\{1\})$ & 0 & $b_{2}$ & $b_{3}$ & $b_{2,3}$ \\
\hline $\mathrm{v}(\mathrm{S}) \mathrm{v}(\mathrm{S}-\{1\})$ & $b_{1}$ & $b_{1,2}-b_{2}$ & $b_{1,3}-b_{3}$ & $b_{1,2,3}-b_{2,3}$ \\
\hline$|\mathrm{S}|$ & 1 & 2 & 2 & 3 \\
\hline$\gamma(|S|)$ & $1 / 3$ & $1 / 6$ & $1 / 6$ & $1 / 3$ \\
\hline$\gamma(|S|)[\mathrm{v}(\mathrm{S})-\mathrm{v}(\mathrm{S}-\{1\})]$ & $b_{1} / 3$ & $\left(b_{1,2}-b_{2}\right) / 6$ & $\left(b_{1,3}-b_{3}\right) / 6$ & $\left(b_{1,2,3}-b_{2,3}\right) / 3$ \\
\hline
\end{tabular}

$b_{1}=E R(0,0,0), \quad b_{1,2}=E R(1,1,0)+E B(1,1,0) b_{2}=E B(0,0,0), \quad b_{3}=E S(0,0,0)$,

$b_{1,2}=E R(1,1,0)+E B(1,1,0), \quad b_{1,3}=E R(1,0,1)+E S(1,0,1), \quad b_{2,3}=E B(0,1,1)+E S(0,1,1)$,

$b_{1,2,3}=E R(1,1,1)+E B(1,1,1)+E S(1,1,1)$.

Then R's profit distributed is

$\overline{E R}=b_{1} / 3+\left(b_{1,2}-b_{2}\right) / 6+\left(b_{1,3}-b_{3}\right) / 6+\left(b_{1,2,3}-b_{2,3}\right) / 3$.

B's and S's profit distributed are

$\overline{E B}=b_{2} / 3+\left(b_{1,2}-b_{1}\right) / 6+\left(b_{2,3}-b_{3}\right) / 6+\left(b_{1,2,3}-b_{1,3}\right) / 3$.

$\overline{E S}=b_{3} / 3+\left(b_{1,3}-b_{1}\right) / 6+\left(b_{2,3}-b_{2}\right) / 6+\left(b_{1,2,3}-b_{1,2}\right) / 3$.

\section{Numerical experiment}

In order to visually explain the feasibility and practicability of the scheme, the numerical experiment will be carried out below. 
Let $p=1, c_{1}=0.6, c_{2}=0.3, c^{\prime}=0.2, s=0.3, s^{\prime}=0.2, a=0.05, a^{\prime}=0.02, l=0.3, \beta=0.05$, the Proportions $Q_{1}=Q_{2}=Q_{3}=20 \%$. Assume the market demand meet the Poisson distribution whose expectation is 10 . The probability density is $f(\xi)=\frac{10^{\xi}}{\xi !}$. The probability distribution is $F(\xi)=\sum_{k=0}^{\xi} \frac{10^{k}}{k !}$. The table below is the comparison of different game patterns.

Conclusions can be draw below:

(1) When the amount of initial inventories is in the interval of $[1,3]$, the loan-to-value ratio is 1 in the pattern of noncooperation, while the amount of initial inventories is in the interval of $[1,5]$ in the pattern of cooperation;

(2) When the amount of initial inventories is in the interval of $[4,6]$, which covers the most proportion of the figure of the probability distribution, the sum earnings of the supply chain in the pattern of cooperation is greater than in the noncooperation;

(3) The sum earnings of the supply chain obtain the maximum value when the the amount of initial inventories is 7 in the pattern of noncooperation, while the the amount of initial inventories is 5 in the pattern of cooperation. That is to say, the alliance of the supply chain can reduce the size requirement for retailers, and raise the earnings at the same time.

Table 3 The comparison of different game patterns

\begin{tabular}{|c|c|c|c|c|c|c|c|c|c|c|}
\hline $\begin{array}{c}\text { Initial } \\
\text { invent } \\
\text { ories }\end{array}$ & \multicolumn{4}{|c|}{ Noncooperation pattern } & \multicolumn{6}{c|}{ Cooperation pattern } \\
\cline { 2 - 11 } & $\mathrm{R}$ & $\mathrm{S}$ & $\mathrm{B}$ & sum & $\begin{array}{c}\text { Loan-t } \\
\text { o-value } \\
\text { ratio }\end{array}$ & $\mathrm{R}$ & $\mathrm{S}$ & $\mathrm{B}$ & sum & $\begin{array}{c}\text { Loan-t } \\
\text { o-value } \\
\text { ratio }\end{array}$ \\
\hline 1 & 0.4696 & 0.1180 & 0.6 & 1.1876 & 1 & 0.4696 & 0.1180 & 0.5994 & 1.1871 & 1 \\
\hline 2 & 0.9291 & 0.2360 & 1.2 & 2.3651 & 1 & 0.9302 & 0.2362 & 1.1928 & 2.3593 & 1 \\
\hline 3 & 1.3225 & 0.3535 & 1.8 & 3.4760 & 1 & 1.3310 & 0.3553 & 1.7563 & 3.4425 & 1 \\
\hline 4 & 1.3194 & 0.4525 & 2.1 & 3.8719 & 0.7937 & 1.5499 & 0.4762 & 2.2312 & 4.2573 & 1 \\
\hline 5 & 1.2443 & 0.5515 & 2.4 & 4.1957 & 0.6032 & 1.4551 & 0.6003 & 2.5289 & 4.5844 & 1 \\
\hline 6 & 0.9688 & 0.6389 & 2.4 & 4.0077 & 0.4762 & 1.1815 & 0.6781 & 2.7186 & 4.5781 & 0.9206 \\
\hline 7 & 0.8036 & 0.7379 & 2.7 & 4.2415 & 0.3855 & 0.8691 & 0.7367 & 2.5951 & 4.2009 & 0.7846 \\
\hline 8 & 0.5354 & 0.8180 & 2.7 & 4.0535 & 0.3175 & 0.5978 & 0.8199 & 2.5954 & 4.0131 & 0.6825 \\
\hline 9 & 0.2640 & 0.9015 & 2.7 & 3.8655 & 0.2646 & 0.3287 & 0.9004 & 2.6033 & 3.8324 & 0.6032 \\
\hline 10 & -0.002 & 1.0012 & 3 & 3.9991 & 0.2222 & 0.0990 & 1.0004 & 2.8482 & 3.9476 & 0.5396 \\
\hline
\end{tabular}

\section{Conclusion}

The research of supply chain finance theory is deepening constantly. The cooperation and game decision-making among enterprises of the supply chain is the core in the problem. To maximize the alliance benefits and make the alliance stable, the method to realize fairly earnings distribution is the basis. In this paper, the decision of the supplier, the retailer and the logistics enterprise are considered in the procedure of the inventory impawn financing under the conditions of uncertain demand and seasonal goods. In different patterns of cooperation in the supply chain, the members choose different of the decision-making and thus obtain different earnings. The conclusion is that to maximum the benefits, the supply chain can adjust the loan-to-value ratio and decision-making in view of the different initial inventory of the retailer. The alliance cooperation can raise the whole earnings of the supply chain as well as reduce the size requirement for retailers, which can bring great benefits to SMEs financing. 


\section{References}

[1] Meir J. Roseblatt. Multi-item inventory system with budgetary constraint: a comparison between the Lagrangian and the fixed cycle approach[J]. International Journal of Production Research, 1981, 19(4):331-339.

[2] Li L, Shubik M, Sobel M J. Control of dividends, capital subscriptions and physical inventories[R]. Working paper. Yale School of Management, 2005.available at: http://ssrn. com/abstract $=690864$.

[3] Protopappa-Sieke M, Seifert R W. Interrelating operational and financial performance measurements in inventory control[J]. European Journal of Operational Research, 2010, 204(3):439-448.

[4] Buzacott J A, Zhang R Q. Inventory Management with Asset-Based Financing[J]. Management Science, 2004, 50(9):1274-1292.

[5] Dada M, Hu Q. Financing newsvendor inventory[J]. Operations Research Letters, 2008, 36(5):569-573.

[6] Gupta D, Wang L. A Stochastic Inventory Model with Trade Credit[J]. Manufacturing \& Service Operations Management, 2009, 11(1):4-18.

[7] Thangam A, Uthayakumar R. Two-echelon trade credit financing for perishable items in a supply chain when demand depends on both selling price and credit period[J]. Computers \& Industrial Engineering, 2009, 57:773-786.

[8] Caldentey R, Haugh M B. Supply contracts with financial hedging[J]. Operations Research, 2009, 7(1):47- 65 .

[9] Gupta D, Wang L. A Stochastic Inventory Model with Trade Credit[J]. Manufacturing \& Service Operations Management, 2009, 11(1):4-18.

[10] Besanko D, Thakor A V. Competitive equilibria in the credit market under asymmetric information[J]. Journal of Economic Theory, 1987, 42: 167 -182.

[11] Chan Y S, Thakor A V. Collateral and competitive equilibria with moral hazard and private information[J]. Journal of Finance, 1987,42:345-364.

[12] Rajan R, Winton A. Covenants and collateral as incentives to monitor[J]. The Journal of Finance, 1995, 50(4): 1113-1146.

[13] Omiccioli M. Trade Credit as Collateral. Working paper, Bank of Italy, 2005. 